\title{
Plasma levels of melatonin, certain cytokines and placental growth factor at non-pharmacological correction of pineal function in pregnant women with intrauterine growth restriction
}

Berbets A. M.

Bukovinian State Medical University, Chernivtsi, Ukraine

e-mail: andriy.berbets@gmail.com

\section{ABSTRACT}

The pineal gland produces the important hormone melatonin, the level of which in the blood of pregnant women decreases in case of placental insufficiency. The effect of pineal dysfunction on the immune system of pregnant women and the angiogenic activity of the placenta during pregnancy remains insufficiently studied.

OBJECTIVE: to study the effect of our method of non-drug correction of pineal function on the state of the cytokine part of the immune system and the synthesis of placental growth factor (PIGF) in pregnant women with placental insufficiency manifested as fetal intrauterine growth restriction (IUGR).

MATERIAL AND METHODS. 46 pregnant women with IUGR at 30-36 weeks of gestation were examined. The group was divided into two subgroups: with non-drug correction of the pineal function $(n=25)$ and without correction $(n=21)$. The method of correction included a set of measures to follow the lighting regimen, activity and sleep for 14 days. The control group consisted of 20 women with uncomplicated pregnancy. Levels of melatonin, PIGF, TNF-a, IL-1 $\beta$, IL-6, IL-4, IL-10 were determined in the venous blood by enzyme-linked immunosorbent assay.

RESULTS. It was established that the concentration of melatonin in the blood of pregnant women with IUGR was significantly reduced, as well as the concentration of PIGF $(p<0.01)$. Significant changes were also found in pregnant women with placental insufficiency, namely, increased concentrations of proinflammatory cytokines, such as TNF-a $(p<0.05), I L-1-\beta(p<0.001)$ and IL- $6(p<0.05)$, comparing to healthy pregnant women. Also, in the group of pregnant women with IUGR, the levels of anti-inflammatory cytokines IL-4 $(p<0.001)$ and IL-10 ( $p<0.001)$ were elevated in comparison to the control group.

After application of the developed complex of non-drug correction of pineal function, the concentration of melatonin in the blood of pregnant women in the subgroup of correction increased significantly, comparing to the subgroup without correction $(p<0.001)$, as well as the level of PIGF $(p<0.05)$. Also, significantly lower levels of proinflammatory cytokines TNF-a, IL-1- $\beta$ and IL-6 were observed in pregnant women in the subgroup of correction $(p<0.01)$. Regarding anti-inflammatory cytokines, there was a decrease in the level of IL-4 and an increase in the level of IL-10 ( $p<0.01)$ under the influence of the non-drug correction.

CONCLUSIONS. When the measures, aimed at non-drug correction of the pineal function, are applied in pregnant women with placental insufficiency, manifested as IUGR, the following changes are observed: increased plasma levels of melatonin and placental growth factor, decreased levels of proinflammatory cytokines. We suggest that the pineal gland exerts its effect on the immune system through melatonin, which moderates the activity of pro- and anti-inflammatory cytokines. Therefore, the influence of inflammation on placental tissue reduces and results in the increase in the concentrations of placental growth factor in the blood of pregnant women.

KEY WORDS: melatonin; placenta; cytokines; placental growth factor; fetal growth restriction. 
The human pineal gland (also called epiphysis) is a gland whose function is to provide circadian and annual biological rhythms of the human body. This function is exerted by the pineal gland through the release of melatonin and serotonin. Melatonin (5-methoxy-N-acetyltryptamine) is the major hormone of the pineal gland. It belongs to the class of indoles, respectively, it easily penetrates the blood-encephalic barrier [1]. Authors suggest that melatonin, when its level in the pineal gland increases, enters the bloodstream by passive diffusion along the concentration gradient; there is also an assumption that this hormone is secreted mainly into the cerebrospinal fluid [2]. Melatonin is considered a «sleep hormone» [3], however, recent studies also report the presence of antioxidant, neuroprotective and immunomodulatory effects of this hormone [4]. Melatonin is considered to be one of the main regulators of such processes as inflammation, metabolism of free radicals, and cell death [5]. The effect of melatonin on the immune system, especially on its cytokine link, has been described by many authors. In particular, it is known that melatonin decreases stress-induced inflammation, [6], reduces the involvement of polymorphonuclear leukocytes into the inflammatory focus [7, 8], modulates the inflammatory response in sepsis by reducing IL-10 [9], inhibits the secretion of proinflammatory interleukins IL- $1-\beta$ and IL-6 [10], as well as TNF- $a$ [11]. Some studies suggest an inverse regulatory effect of cytokines, namely, IL-1- $\beta$, on melatonin secretion [12-15]. Fetal growth restriction (FGR), provoked by placental insufficiency, is accompanied by the increasing of levels of proinflammatory cytokines which results in the triggering of inflammatory mechanisms [16], so it can be expected that melatonin will be effective in FGR.

Two types of melatonin receptors are known: membrane and nuclear. In humans, two functional isoforms of melatonin membrane receptors have been described: M1 and M2. These receptors are localized in the central nervous system (in the hippocampus, hypothalamus, cerebral cortex), retina, ovarian granulosa cells, corpus luteum, coronary arteries, uterus etc. [17]. Both types of melatonin receptors are present in the human uterus [18]. Significant expression of melatonin receptors in the placenta is established [18], and their concentration decreases in case of placental insufficiency and fetal growth restriction syndrome [19].

Melatonin plays an important role in pregnancy: it participates in the successful implantation of a fertilized egg [20], it is actively produced not only by the pineal gland, but also by trophoblasts and placenta [20, 21], it modulates oxidative stress during pregnancy [22], in particular, in case of preeclampsia [23, 24], and also melatonin affects the process of parturition [25]. Melatonin easily crosses the placental barrier; it is thought by some authors to cause the adverse effects on fetal development, especially on the structure and function of the pineal gland of fetus when used exogenously in high doses [26]. It has been known for a long time that maternal melatonin informs the fetus about the season of year and daytime [27], and also affects the circadian rhythm of the newborn [28]. In the experiment by Takayama et al. it was found that healthy rats are more likely to give birth in daylight, while in rats that underwent pinealectomy (including pinealectomy followed by constant administration of high doses of melatonin) lighting stopped affecting the process of labor [25]. According to other data, melatonin does not cause any harmful effects on the development of embryos of mice and rats, even if administered in extremely high doses of $200 \mathrm{mg} / \mathrm{kg} /$ day [29]. It is known, however, that melatonin inhibits the activity of prostaglandin synthetase, while prostaglandins play an important role in the endocrine system of the fetus and its microcirculation [30]. Given the above, we suppose that non-drug methods of correction of function of the pineal gland should be considered as a prior way of treatment during pregnancy.

The role of melatonin in the regulation of angiogenesis has recently attracted the attention of researchers. Interestingly, this hormone affects the growth of blood vessels in different physiological and pathological processes. For example, in tumors, atherosclerotic plaques, as well as in age-related eye lesions and in conditions of hypoxia melatonin inhibits tissue neovascularization, while in gastric ulcer, in skin diseases, as well as in physiological conditions, melatonin, on the contrary, enhances angioneogenesis [31]. Most assume that these effects of melatonin are caused by its interaction with vascular endothelial growth factor (VEGF) and its receptors [31], while very little is known about the interaction of melatonin and placental growth factor (PIGF), which belongs to the «family» of VEGF, but is considered as a separate and key participant in the process of angioneogenesis during pregnancy [32-34]. PIGF is actively produced by the endometrium, trophoblast cells and placenta. When concentration of PIGF is elevated, more active conversion of VEGF to VEGF-2 is observed, which results in accelerated angiogenesis [34]. If this biochemical process is impaired, PIGF activates the process of inflammation, resulting in tissue damage, which is clinically manifested as different pregnancy complications, namely: early pregnancy loss, preeclampsia [35], and fetal growth restriction [36]. Our previous studies have shown that in case of intrauterine growth restriction the concentration of both melatonin and PIGF in umbilical cord blood decreases [37].

Considerable researchers' interest is attracted to the interaction of melatonin with stem cells of the placenta, umbilical cord and fetus. This is important not only from the standpoint of cell transplantation, but also from the point of view of obstetrics, suggesting the acceleration of fetal growth in case of fetal growth restriction.

Taking into account mentioned above data, as well as established in our previous researches facts of the presence of sleep disorders in pregnant women [38], the decrease of levels of melatonin and also changes in concentrations of pro- and anti-inflammatory cytokines in case of placental insufficiency [39], we speculate that the functioning of the pineal gland by the secretion of melatonin should be reflected on the state of the immune system and on the angiogenic activity of the placenta in pregnant women, which became the main hypothesis for this work.

Objective of the study: to establish the effect of our method of nondrug correction of the pineal function on the state of the cytokine part of the immune system and on the synthesis of pro-angiogenic agents by placenta in pregnant women with placental insufficiency manifested as fetal growth restriction.

\section{MATERIALS AND METHODS}

46 women with singleton pregnancies were examined (age range 18 -36 years, mean age $29.3 \pm 3.8$ years); the pregnancies were complicated with placental insufficiency, which was manifested as intrauterine growth restriction syndrome at pregnancy term 30-36 weeks (estimated fetal weight was below 10 percentiles by ultrasound) - the experimental group. The control group consisted of 20 women (age range 18-36 years, mean age $28.2 \pm 3.6$ years) with uncomplicated pregnancy in the same term. Women with severe extragenital pathology, obesity, immune conflicts and signs of intrauterine infection of the fetus were not included in the study groups.

The study was approved at a meeting of the Ethics Commission of the Higher State Educational Institution of Ukraine «Bukovinian State Medical University» (Minutes № 3 from 30.03.2017) and was conducted in compliance with the requirements of The Code of Ethics of the World Medical Association (Declaration of Helsinki, ed. 2013) for experiments involving humans. All patients signed an informed consent to participate in the study.

The experimental group was randomly divided into two subgroups: a subgroup with non-drug correction of the pineal function $(n=25)$, and a subgroup without correction $(n=21)$. The gestational age between the subgroups did not differ significantly: it was $34.3 \pm 1.8$ weeks in the correction subgroup, and $35.0 \pm 2.0$ weeks in the subgroup without correction. Pregnant women, included in the subgroup of non-drug correction of the pineal function with the background of placental insufficiency, followed the next recommendations:

1. Complete refusal from the use of «white» light lamps in the bedroom.

2. Restriction of the use of gadgets (smartphones, computers, etc.) and watching TV after 9 p.m. 
3. Having at least 8 hours of night sleep (except for episodes of awakening).

4. Going to bed not later than 22:00, preferably at the same time.

5. Refusal from taking sleep-improving drugs, in particular, sedatives.

This set of measures developed by us did not include melatonin intake due to the presence of reports about possible teratogenic and fetotoxic effects of exogenous melatonin [26]. This method of non-drug correction was aimed at activating of the pineal gland of patients. The duration of the set of measures was 14 days. Patients did not receive other treatment aimed at improving of function of placenta.

Levels of melatonin, placental growth factor and cytokines were determined in venous blood, which was collected in Vacutainer tubes by a single venipuncture of the peripheral vein on an empty stomach at 8 o'clock in the morning. In order to obtain plasma, the collected blood was centrifuged at room temperature for 5 minutes with an acceleration of $1000 \mathrm{xg}$. Melatonin ELISA and PIGF ELISA diagnostic kits (IBL, Germany) were used to determine the concentration of melatonin and PIGF by enzyme-linked immunosorbent assay. The concentration of pro-inflammatory cytokines, in particular, tumor necrosis factor-a (TNF- $\alpha$ ), interleukin-1- $\beta$ (IL-1- $\beta$ ), interleukin-6 (IL-6), and anti-inflammatory cytokines - interleukin-4 (IL-4) and interleukin-10 (IL-10) were determined by enzyme-linked immunosorbent assay using appropriate diagnostic kits (Vector-Best, Ukraine). The study was performed on a hardware enzyme-linked immunosorbent analyzer with a thermoshaker StatFax 1904 (Awareness Technology, Inc., USA). The results were statistically processed using the MedCalc software package (MedCalc Software, Belgium), with the calculation of Welch-test for different samples. The data are represented as $M \pm m$. Differences were considered significant at $\mathrm{p}<0.05$.

\section{RESULTS AND DISCUSSION}

Levels of melatonin, cytokines and PIGF in the blood of examined pregnant women. The results of the measurement of the levels of the studied parameters before randomization of the experimental group are represented in table 1.

According to the table, in pregnant women with placental insufficiency there was a significant decrease in the concentration of melatonin in the blood plasma $(p=0.0003)$, compared with healthy pregnant women. In addition, the experimental group showed the statistically significant $(p<0.001)$ increase in the level of IL-1- $\beta$, comparing to the control group. Other proinflammatory cytokines, namely TNF- $\alpha$ and IL-6, were also elevated in the blood of women in the experimental group $(p<0.05)$, comparing to normal pregnancies.

The obtained results can be explained as follows. Firstly, , melatonin is produced by the placenta, therefore, in placental insufficiency its production is reduced. Secondly, melatonin modulates the immune response: in particular, it reduces the production of proinflammatory cytokines [40], so in placental insufficiency we observe an increase in levels of proinflammatory cytokines, compared with the same indicators in healthy pregnant women. Regarding TNF-a, our data come in accordance with the previous reports, as it is known that the levels of this factor increase in the presence of fetal growth restriction and preeclampsia [41, 42].

The levels of anti-inflammatory cytokines in women with placental insufficiency were also elevated in comparison with healthy pregnant women: IL- 10 - in 2.4 times $(p<0.001)$ and IL-4 - in 1.6 times $(p<0.01)$.

Our results are partially confirmed by the literature reports. The study conducted by M. Al-Azemi et al. (2017) also found increased levels of pro-inflammatory cytokines, namely IL-6, TNF-a, IL-12, but the level of IL-10 was lowered in pregnant women with intrauterine growth restriction of fetus [43]. We suppose that the increase in anti-inflammatory cytokine levels established in our study, is a sign of the involvement of the body's compensatory mechanisms, which reduce the risk of premature birth.
Plasma concentrations of placental growth factor (PIGF) in women in the group with placental insufficiency were also significantly lowered ( $p$ $<0.01$ ) than in pregnant women in the control group. A decrease in the concentration of PIGF (compared to control, $p<0.01$ ) in the blood plasma of pregnant women included in the experimental group, as we consider, indicates the slowing of angioneogenesis.

Below we represent the results of the study of pregnant women from the subgroup where non-drug correction of the pineal function was performed for 14 days after the initial examination, as well as the results obtained from the women included in the subgroup without non-drug correction. The results of comparing of melatonin levels between the mentioned subgroups are represented in Fig. 1.

As it is shown in Fig. 1, in pregnant women who received our set of measures aimed at activating of the pineal gland, there was a significant elevation of melatonin levels in blood plasma, compared to pregnant women without correction: $160.0 \pm 22.6 \mathrm{pg} / \mathrm{mL}$, in the subgroup without correction $-18.3 \pm 6.0 \mathrm{pg} / \mathrm{mL}(\mathrm{p}<0.001)$. However, the concentration of melatonin in the subgroup of correction did not reach the values of the control group $(231.3 \pm 21.6 \mathrm{pg} / \mathrm{mL}, \mathrm{p}<0.001$ when comparing the correction group and the control group).

Table 1. Levels of melatonin, cytokines and PIGF in the blood plasma of pregnant women with placental insufficiency and in the control group.

$\begin{array}{cc}\text { WOMEN WITH } & \text { WOMEN OF THE } \\ \text { PLACENTAL } & \text { CONTROL GROUP } \\ \text { INSUFFICIENCY }(\mathrm{N}=46) & (\mathrm{N}=\mathbf{2 0})\end{array}$

MELATONIN (PG/ML)

$126.9 \pm 14.9^{*}$

$231.3 \pm 21.6$

TNF-a (PG/ML)

$10.1 \pm 1.4^{*}$

$5.6 \pm 1.5$

IL-1- $\beta$ (PG/ML)

$14.7 \pm 2.1^{\star *}$

$4.0 \pm 0.9$

IL-6 (PG/ML)

$6.9 \pm 1.0^{*}$

$2.7 \pm 1.0$

IL-4 (PG/ML)

$6.0 \pm 0.5^{\star}$

$3.7 \pm 0.6$

IL-10 (PG/ML)

$11.4 \pm 1.5^{\star *}$

$4.7 \pm 3.2$

PLGF (PG/ML)

$118.3 \pm 12.9$ *

$230.0 \pm 30.0$

Notes: ${ }^{*}-p<0.05,{ }^{* *}-p<0.001$ in comparison to the control group

Fig. 1. Comparison of the concentrations of melatonin in the blood plasma of pregnant women with placental insufficiency without correction ( «Melatonin no correction», $n=21$ ), pregnant women from the subgroup of correction ( «Melatonin correction», $n=25$ ) and the control group ("Melatonin control", $n=20$ ).

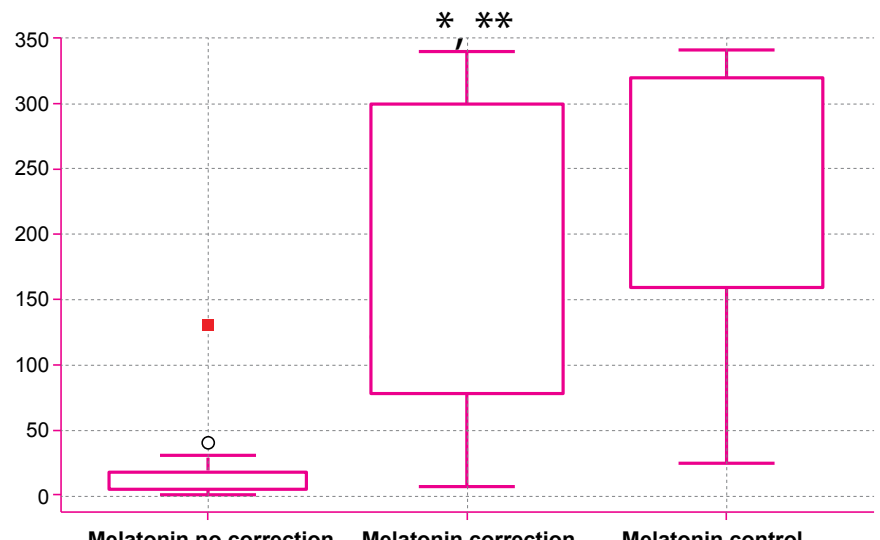

Melatonin no correction Melatonin correction Melatonin control

Notes: * $-p<0.05$ comparing to the control group

${ }^{* *}-p<0.001$ comparing to the group without correction 
SUBGROUP WITHOUT CORRECTION (N = 21)
SUBGROUP WITH CORRECTION $(\mathrm{N}=\mathbf{2 5})$
SUBGROUP WITH CORRECTION $(\mathrm{N}=\mathbf{2 5})$

$5.6 \pm 1.5$

$4.0 \pm 0.9$

$2.7 \pm 2.0$

$3.7 \pm 0.6$

$4.7 \pm 3.2$
Table 2. Levels of TNF- $\alpha$, IL-1- $\beta$ and IL- 6 in the blood plasma of pregnant women in the study groups.

Notes:

* $-p<0.01$ comparing to the control group

** $-p<0.01$ comparing to the subgroup

without correction.
Results of comparison of the levels of cytokines in the blood plasma of pregnant women with placental insufficiency, especially between the subgroup of correction and the subgroup without correction, are represented in table. 2.

We detected that the levels of all studied proinflammatory cytokines, namely TNF- $\alpha$, IL-1- $\beta$ and IL-6, were significantly lower in the correction subgroup than in the subgroup of pregnant women who were not exposed to the measures of activation of work of the pineal gland. Thus, we can affirm that melatonin has the modulating effect on the pro-inflammatory part of the immune system. There was no significant difference in the values of proinflammatory cytokines studied in the blood plasma of pregnant women who were included in the correction subgroup and in the control group of healthy pregnant women.

The levels of anti-inflammatory cytokines in the blood of women from the subgroup of correction changed differently comparing to the

$\checkmark$ Fig. 2. Comparison of PIGF concentrations in the blood of pregnant women with placental insufficiency without correction («PIGF_no correction», $n=21$ ), subgroup of pregnant women with placental insufficiency with non-drug correction of pineal function («PIGF PI correction», $n=25$ ), and the control group («PIGF_control”, $n=20$ ).

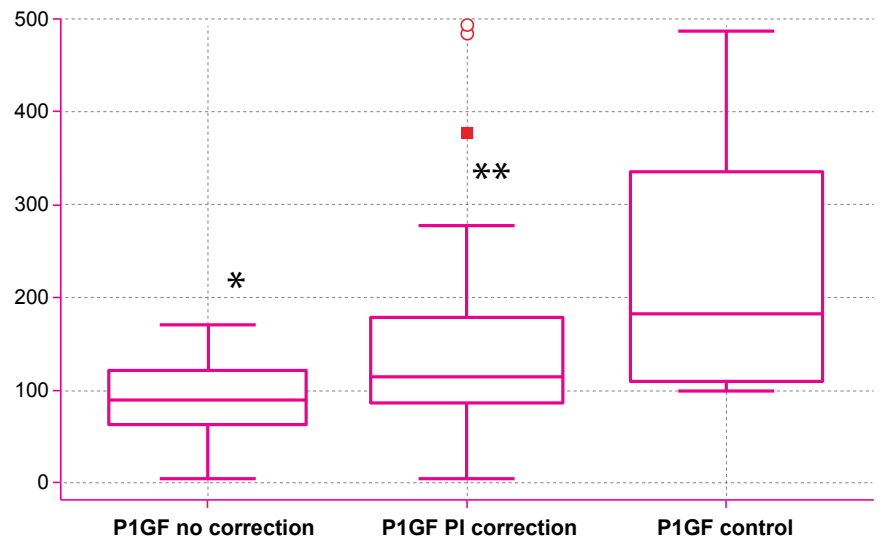

Notes: ${ }^{*}-p<0.01$ comparing to the control group, ${ }^{* *}-p<0,05$ comparing to the group without correction

\section{CONCLUSION}

subgroup of pregnant women with placental insufficiency, who were not exposed to the set of measures developed by us: IL-10 - increased 4.3 times $(p<0,01)$, and IL- 4 - decreased 1.6 times $(p<0,01)$.

We also monitored the concentrations of placental growth factor (PIGF) in the blood plasma of pregnant women with placental insufficiency, who received a complex of non-drug correction of the pineal function. The results are presented in Fig. 2.

The fig. 2 shows that the level of PIGF in the subgroup of correction was $151.8 \pm 26.9 \mathrm{pg} / \mathrm{mL}$, in the subgroup without correction $-84.8 \pm 9.5 \mathrm{pg} / \mathrm{mL}$, and in the control group $-230.0 \pm 30.0 \mathrm{pg} / \mathrm{mL}$. In other words, we found a decrease in the concentration of PIGF in 2.7 times (compared with healthy pregnant women, $p<0.01$ ) in the blood of patients included in the subgroup without non-drug correction. In contrast, in the blood plasma of pregnant women exposed to a set of non-drug measures aimed at improving of the pineal function, the concentration of PIGF was significantly higher in comparison to the subgroup without correction $(p<0.05)$ and did not differ significantly from the control group.

It should be noted that the use of melatonin for the treatment of fetal growth restriction is generally not a new idea. However, most of such studies are performed on animals. In recent studies on this problem laboratory mice were used [44, 45], fetal growth restriction was modulated artificially, for example, by administering cadmium to mice [45], and melatonin was administered to animals in relatively high doses, such as $5 \mathrm{mg}$ melatonin per $1 \mathrm{~mL}$ of drinking water [44], causing accelerated fetal growth. In medical practice, however, experts often focus on studying of the neuroprotective effect of exogenous melatonin on the fetus with fetal growth restriction [46]. We did not find publications that describe the same or similar to our method of non-drug correction of pineal function, in particular, at pregnancy in women.

A promising area of research is the study of the interaction of melatonin with stem cells. Recently published papers have reported that this hormone exerts a proliferative and anti-inflammatory effect on adipose tissue-derived mesenchymal stem cells [47], accelerates proliferation and modulates the differentiation of nerve stem cells [48], and even restores the lost under the influence of TNF-a stemness of mesenchymal bone marrow cells [49]; therefore, melatonin may improve the results of stem cell transplantation. Given the effect of melatonin on stem cells, we suppose that our method of correction of pineal gland's function can increase the efficiency of isolation, banking and subsequent use of stem cells derived from placenta and umbilical cord blood.

When the measures aimed at non-drug correction of pineal function of are applied in pregnant women with placental insufficiency, manifested as intrauterine growth restriction of the fetus, the next changes are observed: the elevation of plasma concentrations of melatonin, the decrease of levels of proinflammatory cytokines and the increase of concentrations of placental growth factor PIGF. Thus, we suggest that the pineal gland exerts its effect on the immune system through melatonin, which moderates the activity of pro- and anti-inflammatory cytokines, thereby reducing the influence of inflammation on placental tissue, what results in ther increase of placental growth factor PIGF concentrations in the blood of pregnant women. 


\section{REFERENCES}

1. Grishchenko VI. Rol' epifiza v iziologii i patologii zhenskoy polovoy sistemy [The role of the pineal gland in the physiology and pathology of the female reproductive system]. Khar'kov - Kharkiv, 1979. 248 p. [In Russian]

2. Abe M, Kawaguchi H, Miura N, Akioka K, Ushikai M, Oi S, Yukawa A, et al. Diurnal Variation of Melatonin Concentration in the Cerebrospinal Fluid of Unanesthetized Microminipig. In Vivo. 2018; 32(3):583-590. D0l: 10.21873/invivo.11279.

3. Zisapel N. New perspectives on the role of melatonin in human sleep, circadian rhythms and their regulation. Br J Pharmacol. 2018; 175(16):3190-3199. D0I: 10.1111/bph.14116.

4. Claustrat B, Leston J. Melatonin: Physiological effects in humans. Neurochirurgie. 2015; 61(2-3):77-84. D0I: 10.1016/j.neuchi.2015.03.002.

5. Tarocco A, Caroccia N, Morciano G, Wieckowski MR, Ancora G, Garani G, et al. Melatonin as a master regulator of cell death and inflammation: molecular mechanisms and clinical implications for newborn care. Cell Death Dis. 2019; 10(4):317. DOI: 10.1038/s41419-019-1556-7.

6. Yi WJ, Kim TS. Melatonin protects mice against stress-induced inflammation through enhancement of M2 macrophage polarization. Int Immunopharmacol. 2017; 48:146-158. DOI: 10.1016/j.intimp.2017.05.006.

7. Mayo JC, Sainz RM, Tan DX, Hardeland R, Leon J, Rodriguez C, et al. Anti-inflammatory actions of melatonin and its metabolites, N1-acetyl-N2-formyl-5methoxykynuramine (AFMK) and N1-acetyl-5-methoxykynuramine (AMK), in macrophages. J Neuroimmunol. 2005; 165(1-2):139-49. D0l: 10.1016/j. jneuroim.2005.05.002.

8. Najafi M, Shirazi A, Motevaseli E, Rezaeyan AH, Salajegheh A, Rezapoor S. Melatonin as an anti-inflammatory agent in radiotherapy. Inflammopharmacology. 2017; 25(4):403-413. DOI: 10.1007/s10787-017-0332-5

9. Ersoy ÖF, Özkan N, Özsoy Z, Kayaoğlu HA, Yenidoğan E, Çelik A, et al. Effects of melatonin on cytokine release and healing of colonic anastomoses in an experimental sepsis model. Ulus Travma Acil Cerrahi Derg. 2016; 22(4):315-21. DOI: 10.5505/tjtes.2015.49465.

10. Skwarlo-Sonta K, Majewski P, Markowska M, Oblap R, Olszanska B. Bidirectional communication between the pineal gland and the immune system. Can J Physiol Pharmacol. 2003; 81(4):342-9. D0I: 10.1139/y03-026.

11. Haddadi GH, Fardid R. Oral administration of melatonin modulates the expression of tumor necrosis factor-a (TNF-a) gene in irradiated rat cervical spinal cord. Rep Pract Oncol Radiother. 2015; 20(2):123-7. DOI: 10.1016/j.rpor.2014.11.003.

12. Herman AP, Krawczyńska A, Bochenek J, Dobek E, Herman A, Tomaszewska-Zaremba D. LPS-induced inflammation potentiates the IL-1 $\beta$-mediated reduction of LH secretion from the anterior pituitary explants. Clin Dev Immunol. 2013; 2013:926937. DOI: 10.1155/2013/926937.

13. Meng X, Li Y, Li S, Zhou Y, Gan RY, XU DP, Li HB. Dietary Sources and Bioactivities of Melatonin. Nutrients. 2017; 9(4):367. DOI: 10.3390/nu9040367.

14. Zhang $M$, Wang T, Chen HM, Chen YQ, Deng YC, Li YT. Serum levels of interleukin-1 beta, interleukin- 6 and melatonin over summer and winter in kidney deficiency syndrome in Bizheng rats. Chin Med Sci J. 2014; 29(2):107-11. DOI: 10.1016/s1001-9294(14)60037-7.

15. Herman AP, Bochenek J, Skipor J, Król K, Krawczyńska A, Antushevich H, et al. Interleukin-1 $\beta$ Modulates Melatonin Secretion in Ovine Pineal Gland: Ex Vivo Study. Biomed Res Int. 2015; 2015:526464. DOl: 10.1155/2015/526464.

16. Burton GJ, Jauniaux E. Pathophysiology of placental-derived fetal growth restriction. Am J Obstet Gynecol. 2018; 218(2S):S745-S761. DOI: 10.1016/j. ajog.2017.11.577.

17. Dubocovich ML, Delagrange P, Krause DN, Sugden D, Cardinali DP, Olcese J. International Union of Basic and Clinical Pharmacology. LXXV. Nomenclature, classification, and pharmacology of G protein-coupled melatonin receptors. Pharmacol Rev. 2010; 62(3):343-80. DOI: 10.1124/pr.110.002832.

18. Richter $H G$, Hansell JA, Raut $S$, Giussani DA. Melatonin improves placental efficiency and birth weight and increases the placental expression of antioxidant enzymes in undernourished pregnancy. J Pineal Res. 2009; 46(4):357-64. DOl: 10.1111/j.1600-079X.2009.00671.x.

19. Berbets AM, Davydenko IS, Barbe AM, Konkov DH, Albota OM, Yuzko OM. Melatonin $1 \mathrm{~A}$ and 1B Receptors' Expression Decreases in the Placenta of Women with Fetal Growth Restriction. Reprod Sci. 2021; 28(1):197-206. D0I: 10.1007/s43032-020-00285-5.

20. Soliman $A$, Lacasse $A A$, Lanoix $D$, Sagrillo-Fagundes $L$, Boulard $V$, Vaillancourt $C$. Placental melatonin system is present throughout pregnancy and regulates villous trophoblast differentiation. J Pineal Res. 2015; 59(1):38-46. D0I: 10.1111/jpi.12236.

21. Teixeira AAC, Simões MJ, Wanderley-Teixeira V, Soares JRJM. Evaluation of the implantation in pinealectomized and/or submitted to the constant illumination rats. Int J Morphol. 2004; 22(3):189-194.

22. Richter HG, Hansell JA, Raut $S$, Giussani DA. Melatonin improves placental efficiency and birth weight and increases the placental expression of antioxidant enzymes in undernourished pregnancy. J Pineal Res. 2009; 46(4):357-64. DOI: 10.1111/j.1600-079X.2009.00671.x.

23. Reiter RJ, Tan DX, Korkmaz A, Rosales-Corral SA. Melatonin and stable circadian rhythms optimize maternal, placental and fetal physiology. Hum Reprod Update. 2014; 20(2):293-307. DOI: 10.1093/humupd/dmt054.

24. Marseglia L, D'Angelo G, Manti S, Reiter RJ, Gitto E. Potential Utility of Melatonin in Preeclampsia, Intrauterine Fetal Growth Retardation, and Perinatal Asphyxia. Reprod Sci. 2016; 23(8):970-7. DOI: 10.1177/1933719115612132.

25. Takayama $\mathrm{H}$, Nakamura $Y$, Tamura $\mathrm{H}$, Yamagata $Y$, Harada $A$, Nakata $M$, et al. Pineal gland (melatonin) affects the parturition time, but not luteal function and fetal growth, in pregnant rats. Endocr J. 2003; 50(1):37-43. DOI: 10.1507/endocrj.50.37.

26. Reznikov AG, Pishak VP, Nosenko ND, et al. Prenatal'nyy stress i neyroendokrinnaya patologiya [Prenatal stress and neuroendocrine pathology]. Chernovtsy Chernivtsi, 2004. 351 p. [In Russian]

27. Thorburn GD, Challis JR. Endocrine control of parturition. Physiol Rev. 1979; 59(4):863-918. D0I: 10.1152/physrev.1979.59.4.863.

28. Davis FC, Mannion J. Entrainment of hamster pup circadian rhythms by prenatal melatonin injections to the mother. Am J Physiol. 1988; 255(3 Pt 2):R439-48. DOI: 10.1152/ajpregu.1988.255.3.R439.

29. Chan WY, Ng TB. Development of pre-implantation mouse embryos under the influence of pineal indoles. J Neural Transm Gen Sect. 1994; 96(1):19-29. D0I: $10.1007 / \mathrm{BF} 01277925$.

30. Leach CM, Thorburn GD. A comparison of the inhibitory effects of melatonin and indomethacin on platelet aggregation and thromboxane release. Prostaglandins. 1980; 20(1):51-6. DOI: 10.1016/0090-6980(80)90005-2.

31. Ma Q, Reiter RJ, Chen Y. Role of melatonin in controlling angiogenesis under physiological and pathological conditions. Angiogenesis. 2020; 23(2):91-104. D0I: 10.1007/s10456-019-09689-7.

32. Umapathy A, Chamley LW, James JL. Reconciling the distinct roles of angiogenic/anti-angiogenic factors in the placenta and maternal circulation of normal and pathological pregnancies. Angiogenesis. 2020; 23(2):105-117. DOI: 10.1007/s10456-019-09694-w. 
33. Ribatti $D$. The discovery of the placental growth factor and its role in angiogenesis: a historical review. Angiogenesis. 2008; 11(3):215-21. D0I: 10.1007/s10456008-9114-4.

34. Nejabati HR, Latifi Z, Ghasemnejad T, Fattahi A, Nouri M. Placental growth factor (PIGF) as an angiogenic/inflammatory switcher: lesson from early pregnancy Iosses. Gynecol Endocrinol. 2017; 33(9):668-674. DOI: 10.1080/09513590.2017.1318375.

35. Herraiz I, Llurba E, Verlohren S, Galindo A. Spanish Group for the Study of Angiogenic Markers in Preeclampsia. Update on the Diagnosis and Prognosis of Preeclampsia with the Aid of the sFlt-1/ PIGF Ratio in Singleton Pregnancies. Fetal Diagn Ther. 2018; 43(2):81-89. D0I: 10.1159/000477903.

36. Vrachnis $N$, Kalampokas $E$, Sifakis $S$, Vitoratos $N$, Kalampokas $T$, Botsis D, et al. Placental growth factor (PIGF): a key to optimizing fetal growth. J Matern Fetal Neonatal Med. 2013; 26(10):995-1002. D0I: 10.3109/14767058.2013.766694.

37. Berbets AM, Barbe AM, Andriiets OA, Andriiets AV, Yuzko OM. Melatonin Levels Decrease in the Umbilical Cord in Case of Intrauterine Growth Restriction. J Med Life. 2020; 13(4):548-553. DOI: 10.25122/jml-2020-0128.

38. Heo JS, Pyo S, Lim JY, Yoon DW, Kim BY, Kim JH, et al. Biological effects of melatonin on human adipose-derived mesenchymal stem cells. Int J Mol Med. 2019; 44(6):2234-2244. DOI: 10.3892/ijmm.2019.4356.

39. Li H, Zhang Y, Liu S, Li F, Wang B, Wang J, et al. Melatonin Enhances Proliferation and Modulates Differentiation of Neural Stem Cells Via Autophagy in Hyperglycemia. Stem Cells. 2019; 37(4):504-515. DOI: 10.1002/stem.2968.

40. Wang X, Liang T, Qiu J, Qiu X, Gao B, Gao W, et al. Melatonin Reverses the Loss of Stemness Induced by TNF-a in Human Bone Marrow Mesenchymal Stem Cells through Upregulation of YAP Expression. Stem Cells Int. 2019; 2019:6568394. DOI: 10.1155/2019/6568394.

41. Berbets $A M$. Rozladi snu u vagitnikh iz zatrimkoyu vnutrishn'outrobnogo rozvitku ploda. Visnik [Sleep disorders in pregnant women with intrauterine growth retardation]. Vinnits'kogo natsional'nogo medichnogo universitetu - Bulletin of Vinnytsia National Medical University. 2018; 22(1):160-163. [In Ukrainian]

42. Berbets A, Koval H, Barbe A, Albota O, Yuzko O. Melatonin decreases and cytokines increase in women with placental insufficiency. J Matern Fetal Neonatal Med. 2021; 34(3):373-378. DOI: 10.1080/14767058.2019.1608432.

43. Najafi M, Shirazi A, Motevaseli $E$, Rezaeyan $A H$, Salajegheh $A$, Rezapoor S. Melatonin as an anti-inflammatory agent in radiotherapy. Inflammopharmacology. 2017; 25(4):403-413. DOl: 10.1007/s10787-017-0332-5.

44. Peraçoli JC, Rudge MV, Peraçoli MT. Tumor necrosis factor-alpha in gestation and puerperium of women with gestational hypertension and pre-eclampsia. Am $\mathrm{J}$ Reprod Immunol. 2007; 57(3):177-85. D0I: 10.1111/j.1600-0897.2006.00455.x.

45. Alijotas-Reig J, Esteve-Valverde E, Ferrer-Oliveras R, Llurba E, Gris JM. Tumor Necrosis Factor-Alpha and Pregnancy: Focus on Biologics. An Updated and Comprehensive Review. Clin Rev Allergy Immunol. 2017; 53(1):40-53. DOI: 10.1007/s12016-016-8596-X.

46. Al-Azemi M, Raghupathy R, Azizieh F. Pro-inflammatory and anti-inflammatory cytokine profiles in fetal growth restriction. Clin Exp Obstet Gynecol. 2017; 44(1):98-103.

47. Renshall LJ, Morgan HL, Moens H, Cansfield D, Finn-Sell SL, Tropea T, et al. Melatonin Increases Fetal Weight in Wild-Type Mice but Not in Mouse Models of Fetal Growth Restriction. Front Physiol. 2018; 9:1141. DOI: 10.3389/fphys.2018.01141.

48. Hua-Long Zhu, Xue-Ting Shi, Xiao-Feng Xu, Guo-Xiang Zhou, Yong-Wei Xiong, Song-Jia Yi, et al. Melatonin protects against environmental stress-induced fetal growth restriction via suppressing ROS-mediated GCN2/ATF4/BNIP3-dependent mitophagy in placental trophoblasts. Redox Biol. 2021; 40:101854. D0I: 10.1016/j.redox.2021.101854.

49. Miller SL, Yawno T, Alers NO, Castillo-Melendez M, Supramaniam VG, VanZyl N, et al. Antenatal antioxidant treatment with melatonin to decrease newborn neurodevelopmental deficits and brain injury caused by fetal growth restriction. J Pineal Res. 2014; 56(3):283-94. D0I: 10.1111/jpi.12121.

50. Berbets A, Konkov D, Bulavenko 0, Taran 0, Bakun 0. Melatonin, placental growth factor and placental hormones at placental insufficiency. Cell and Organ Transplantology. 2019; 7(2):103-107. DOI: 10.22494/cot.v7i2.100. 